\title{
Erratum: Improving the quality of nursing documentation: An action research project
}

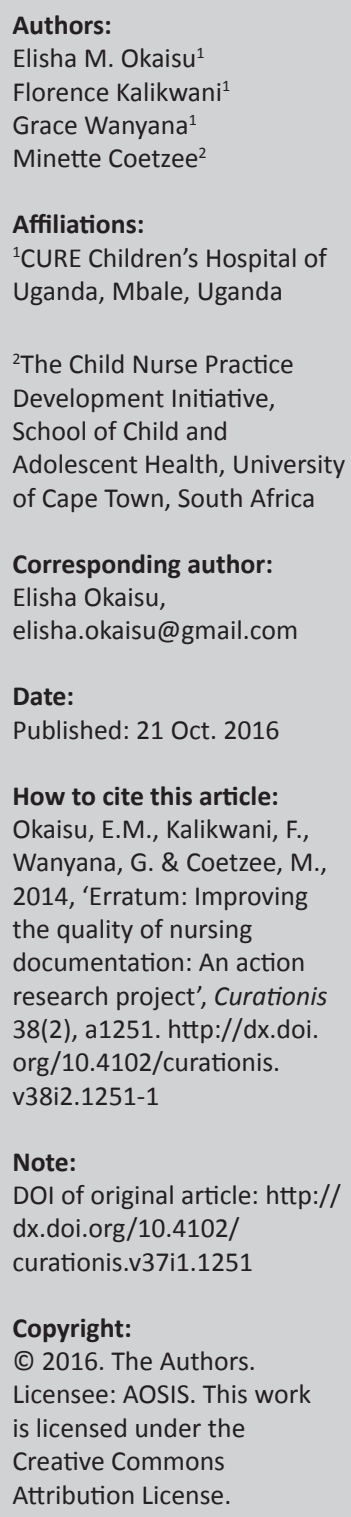

Copyright:

(C) 2016. The Authors. Licensee: AOSIS. This work

is licensed under the

Creative Commons

Attribution License.

This erratum is published to correct the DOI volume and issue information for article 'Improving the quality of nursing documentation: An action research project' in the 'How to site' section.

Incorrect DOI: http:/ / dx.doi.org/10.4102/curationis.v37i1.1251

Correct DOI: http:/ /dx.doi.org/10.4102/curationis.v38i2.1251-1 